\title{
Design of a 1-MV Induction Injector for the Relativistic Klystron Two-Beam Accelerator
}

\author{
D. E. Anderson, S. Eylon, S. Lidia, L. Reginato, D. Vanecek \& S. Yu, LBNL \\ T. Houck \& G. A. Westenskow (contact), LLNL \\ E. Henestroza, U.C. Davis
}

This paper was prepared for submittal to the

1997 Particle Accelerator Conference

Vancouver, B. C. Canada

May 12-16, 1997

May 1997

This is a preprint of a paper intended for publication in a journal or proceedings. Since changes may be made before publication, this preprint is made available with the understanding that it will not be cited or reproduced without the permission of the author. 


\section{DISCLAIMER}

This document was prepared as an account of work sponsored by an agency of the United States Government. Neither the United States Government nor the University of California nor any of their employees, makes any warranty, express or implied, or assumes any legal liability or responsibility for the accuracy, completeness, or usefulness of any information, apparatus, product, or process

disclosed, or represents that its use would not infringe privately owned rights. Reference herein to any specific commercial product, process, or service by trade name, trademark, manufacturer, or otherwise, does not necessarily constitute or imply its endorsement, recommendation, or favoring by the United States Government or the University of California. The views and opinions of authors expressed herein do not necessarily state or reflect those of the United States Government or the University of California, and shall not be used for advertising or product endorsement purposes. 


\title{
DESIGN OF A 1-MV INDUCTION INJECTOR FOR THE RELATIVISITIC KLYSTRON TWO-BEAM ACCELERATOR
}

\author{
D. E. Anderson, S. Eylon, S. Lidia, L. Reginato, D. Vanecek, S. Yu, \\ Lawrence Berkeley National Laboratory, Berkeley, CA 94720 USA, \\ T. Houck, G. A.Westenskow, Lawrence Livermore National Laboratory, Livermore, CA 94550 USA \\ E. Henestroza, University of California, Davis, CA 95616 USA,
}

\section{Abstract}

A Relativistic Klystron Two-Beam Accelerator (RK-TBA) is envisioned as a rf power source upgrade of the Next Linear Collider. Construction of a prototype, called the RTA, based on the RK-TBA concept has commenced at the Lawrence Berkeley National Laboratory. This prototype will be used to study physics, engineering, and costing issues involved in the application of the RK-TBA concept to linear colliders. The first half of the injector, a $1 \mathrm{MeV}, 1.2 \mathrm{kA}, 300 \mathrm{~ns}$ induction electron gun, has been built and is presently being tested. The design of the injector cells and the pulsed power drive units are presented in this paper.

\section{INTRODUCTION}

A Lawrence Berkeley National Laboratory (LBNL) and Lawrence Livermore National Laboratory (LLNL) collaboration has been studying rf power sources based on the Relativistic Klystron Two-Beam Accelerator (RKTBA) concept for several years [1,2]. The collaboration has prepared a preliminary design study for a RF power source suitable for the NLC [3]. This RF power source, referred to as the TBNLC, is comprised of subunits, each approximately $340 \mathrm{~m}$ in length with 150 extraction structures generating $360 \mathrm{MW}$ per structure. The number of subunits is dependent on the power requirement for the collider, e.g. 76 subunits are required for a $1.5-\mathrm{TeV}$ collider. A test facility, called the RTA, has been established at LBNL[4] to verify the analysis used in the design study. The primary effort of the facility is the construction of a prototype TBNLC subunit that will permit the study of technical issues, system efficiencies, and costing. In this paper, we will discuss the development of the RTA electron source and it's pulsed power system, which has recently been constructed and is now undergoing testing.

\section{INDUCTION ELECTRON GUN}

An illustration of the 1-MV, 1.2-kA induction electron source is shown in Figure 1. The cores are segmented radially to reduce the individual aspect $(\Delta \mathrm{r} / \Delta \mathrm{z})$ ratios with each core driven separately at about $14 \mathrm{kV}$. The lower aspect ratio reduces the variation in core impedance during the voltage pulse simplifying the pulse forming network (PFN) design. We chose a constant radius insulator design. This design increased the METGLAS[5] core volume by about $10 \%$, but the added cost was recovered in reduced insulator and fabrication costs. Figure 2 is a photograph of the completed cathode-half of the gun undergoing initial pulsed power tests. Currently, the cathode-half gun is being used to test various insulator configurations. The test results will be incorporated into the RTA's induction accelerator design.

A novel feature of the gun design is the insulator. We are doing high voltage testing with a single, $30 \mathrm{~cm}$ ID, PYREX[6] tube for the insulator with no intermediate electrodes. The average gradient along the

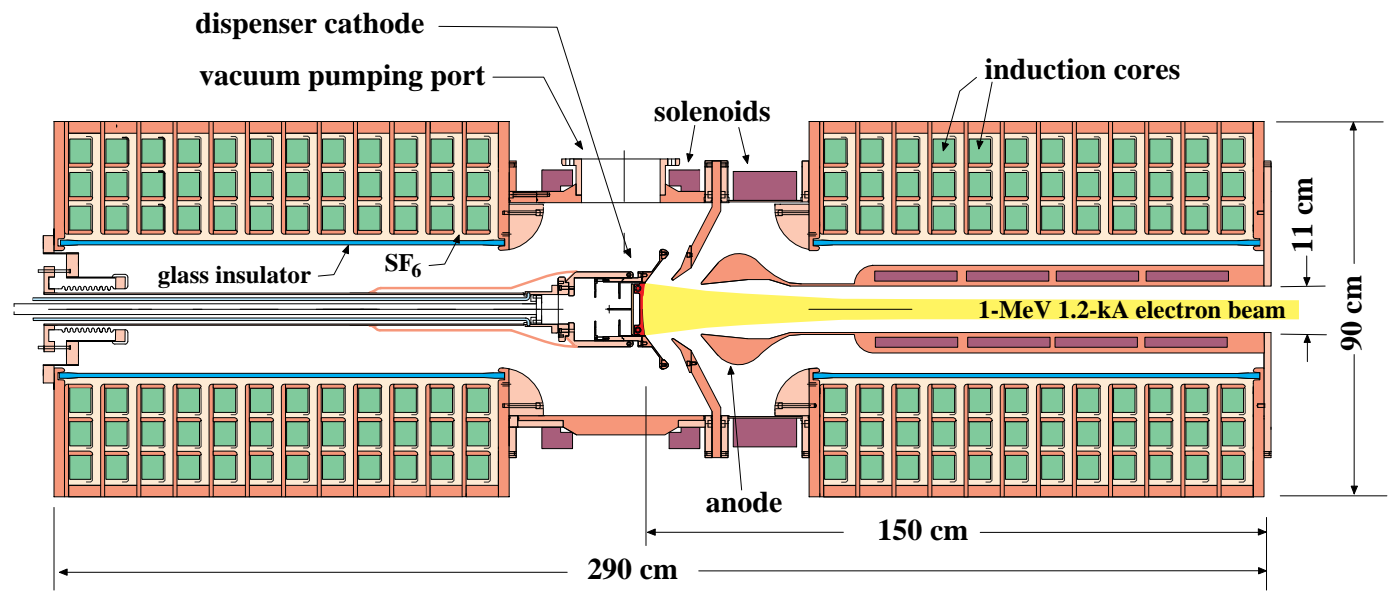

Figure 1. Illustration of the RTA gun, a 1.2-kA, 1-MeV induction electron source. 


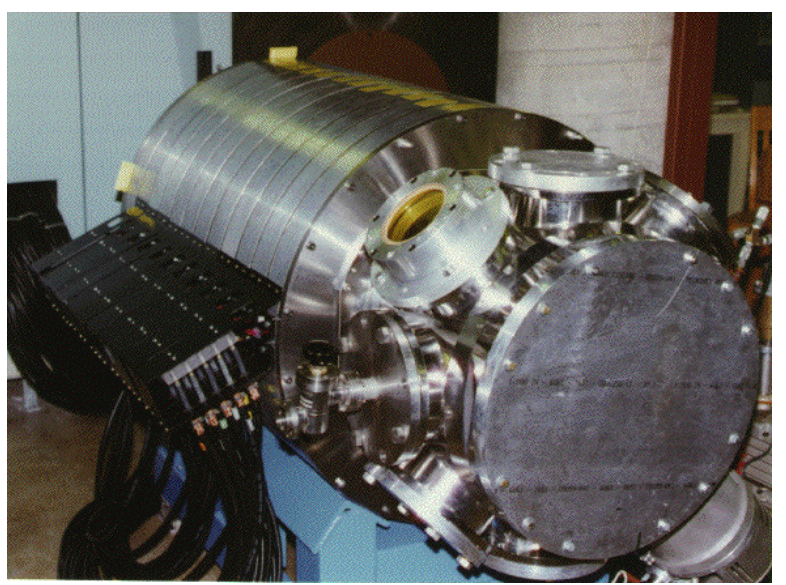

Figure 2. Photograph of the assembled cathode-half of gun. The cathode will be located within the pumping spool. Flange for the anode-half of gun is blanked off.

insulator at the operating voltage of $500 \mathrm{kV}$ is about 5.1 $\mathrm{kV} / \mathrm{cm}$. Maximum fields at the triple points, the intersection of insulator, vacuum, and metal, is less than $3.5 \mathrm{kV} / \mathrm{cm}$. Maximum surface fields in the cathode half of the gun are about $85 \mathrm{kV} / \mathrm{cm}$. The maximum field is about $116 \mathrm{kV} / \mathrm{cm}$ on the anode stalk. The rationale for using PYREX is to explore methods of reducing the costs of induction injectors. PYREX is significantly less expensive than ceramic, and additional savings are realized by avoiding intermediate electrodes. Since there is additional risk associated with this approach, our design allows for the addition of intermediate electrodes and/or substitution of a ceramic insulator with minimal impact to schedule or expense. However, the initial high-voltage tests on the cathode-side insulator are encouraging.

\section{PULSED POWER SYSTEM}

The pulsed power system will consist of a $20-\mathrm{kV}$ Energy Storage Bank Charging Power Supply, 6-kJ Energy Storage Bank, two Command Resonant Charging Chassis, 24 Switched Pulse Forming Networks, and four Induction Core Reset Pulsers, half of which is shown in Figure 3. A photograph of one PFN is shown in Figure 4. Each PFN will drive a single 3-core induction cell. A sample pulse for a single cell with a $40 \Omega$ resistor simulating beam loading is shown in Figure 5.

Segmenting the core in the induction cell and driving the individual core segments avoids a high-voltage stepup transformer. This reduces the developmental effort needed to achieve a "good" flattop pulse (minimal energy variation) with fast risetime and improves the efficiency of the overall pulsed power system. Our system of lowvoltage PFNs driving multiple core induction cells is similar to the system envisioned for the extraction section in the TBNLC design. For the core material, we choose METGLAS alloy 2605SC instead of the 2714AS,

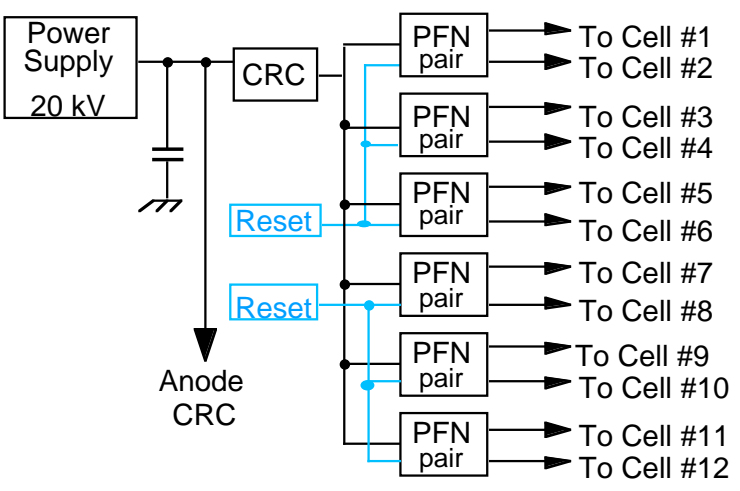

Figure 3. Block diagram of the pulsed power system for the cathode half of the RTA gun.

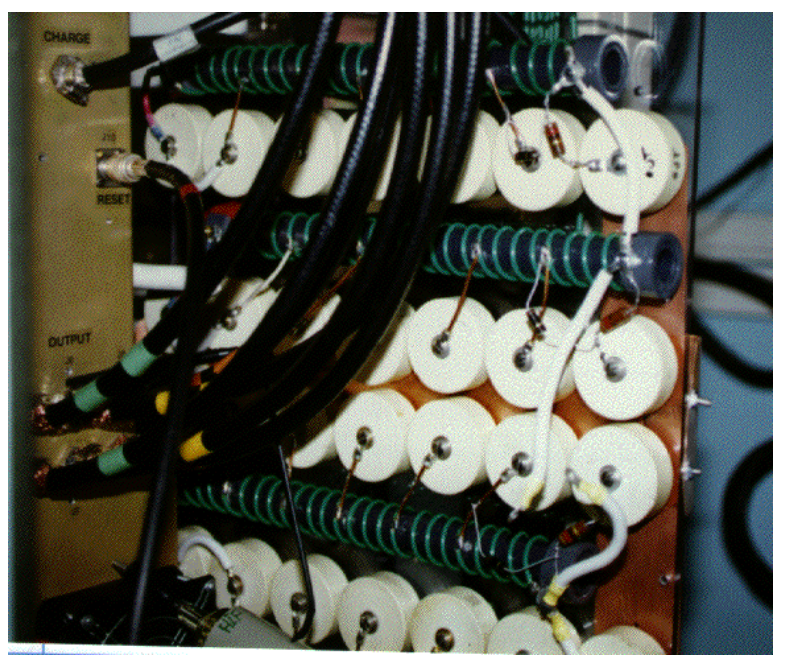

Figure 4. Photograph of single PFN used for driving a gun induction cell. The PFN is comprised of multiple LC stages charged to about $28 \mathrm{kV}$ and uses thyratron switching.

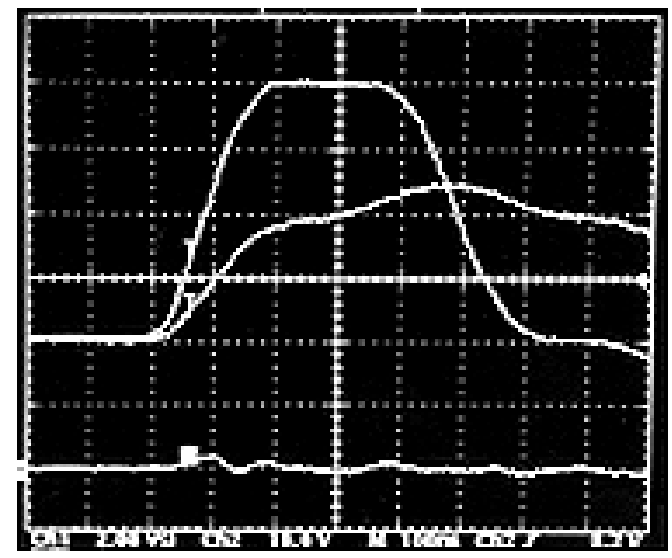

Figure 5. Oscilloscope trace of pulsed gap voltage applied to a single induction cell. Top trace is voltage (10 kV/div) and middle trace is current (4 kA/div). Time scale : $100 \mathrm{~ns} / \mathrm{div}$. 
the preferred material for the TBNLC, due to the larger inner diameter gun cores. In the RTA gun configuration, the larger flux swing of $2605 \mathrm{SC}$ was of greater importance than the lower loss per unit volume of 2714AS. The RTA extraction section will use 2714AS to permit an accurate measurement of the pulsed power system efficiency expected for the TBNLC.

Design of the switched PFNs follows easily from published METGLAS core loss data[7]. For the RTA induction cells, a flux swing of $2.6 \mathrm{~T}$ in $400 \mathrm{~ns}$ (FWHM) results in a magnetization rate of $6.5 \mathrm{~T} / \mu \mathrm{s}$. At this rate, a loss density of $1800 \mathrm{~J} / \mathrm{m}^{3}$ translates into $30 \mathrm{~J}$ lost in a cell with $16.7 \times 10^{3} \mathrm{~cm}^{3}$ of 2605SC METGLAS. For a cell input voltage of $14 \mathrm{kV}$ applied for $400 \mathrm{~ns}$, these losses require that $5900 \mathrm{~A}$ be supplied to the three radial cores. An additional $3600 \mathrm{~A}$ is required to supply beam current (1200 A x 3 cores/cell), resulting is a total current of 9 $\mathrm{kA}$. The required drive impedance is then $1.5 \Omega$, which is provided by the PFN module shown in Figure 3.

Achieving the fast risetime necessary to minimize the volt-seconds required for the injector cores presented a challenge. Budget constraints coupled with the large availability of EEV CX1538 thyratrons from the ATA program at LLNL made these tubes an attractive option. However, their poor time rate of current change $(4 \mathrm{kA} / \mu \mathrm{s}$ rating) made them questionable for this application, which requires about $40 \mathrm{kA} / \mu \mathrm{s}$. A variety of techniques were tried to decrease the risetime. In a $1.5 \Omega$ system, stray circuit inductances must be maintained at or below $100 \mathrm{nH}$ to achieve a $10-90 \%$ risetime of $150 \mathrm{~ns}$. This was accomplished by placing the thyratron between two current sheets connecting the PFN output to the output cables. The ionization time of the thyratron was substantially reduced by applying a 1-2 A pre-pulse to the keep-alive grid 300-400 ns prior to the arrival of the main control-grid pulse. Despite all these improvements, ceramic thyratrons, such as the Triton F-130, may have to be used in the final injector system to overcome excessive stray inductances and capacitance.

An area of concern is the consistency of the METGLAS cores. Several core materials were tested at the RTA Test Facility to establish a data base for design studies. However, this testing did not address the issue of consistency between cores of the same material. We now have a data base including the 38 cores of METGLAS alloy $2605 \mathrm{SC}$ used in the construction of the cathode-half of the gun. Figure 6 shows the energy loss per unit volume for these cores extrapolated to a magnetization rate, $\mathrm{dB} / \mathrm{dt}$, of $5 \mathrm{~T} / \mu \mathrm{s}$. The cores used $20 \mu \mathrm{m}$ thick 2605SC layers with MYLAR insulation and achieved an average packing fraction of $76 \%$, minimum of $72 \%$ and maximum of $78 \%$. The cores had a radial thickness of $5.8 \mathrm{~cm}$ with an inner radius of $19 \mathrm{~cm}, 27 \mathrm{~cm}$, or $35 \mathrm{~cm}$. The small, medium, and large cores in Figure 6 refer to the different inner radii. The three horizontal lines represent the average loss per volume for the respective core sizes. The smaller the core radius, the higher the loss per volume, as shown in the figure. However, total loss per core for the 38 cores was approximately the same with no significant dependence on core size.

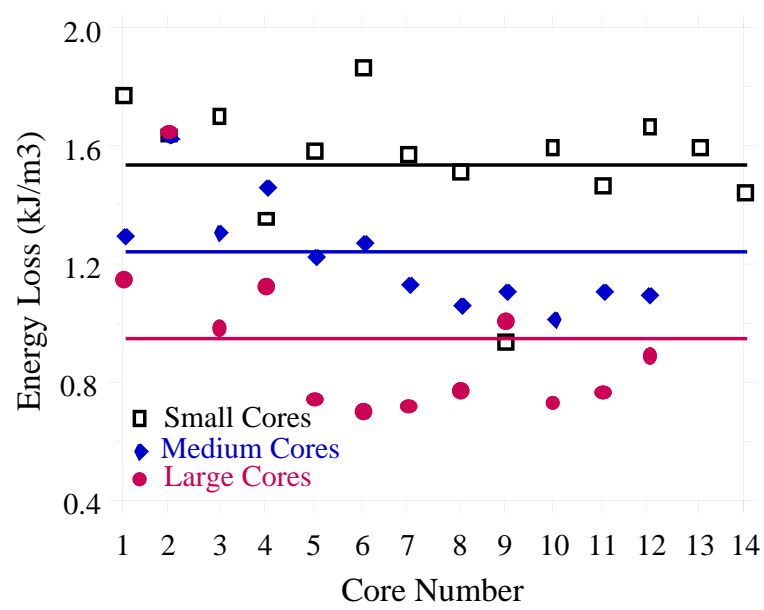

Figure 6. Test results for the METGLAS alloy 2605SC cores.

The standard deviation in loss per volume for the small and medium cores was $14 \%$ and the large core was $29 \%$. However, by matching the cores, the standard deviation for a three core cell was reduced to $4 \%$. If the core losses vary sufficiently, it becomes necessary to tailor individual PFNs to adjust for the different cell loads. For a large relativistic klystron, matching cell cores should permit acceptable energy loss variation.

\section{ACKNOWLEDGMENTS}

The work was performed under the auspices of the U.S. Department of Energy by LLNL under contract W-7405-ENG-48, and by LBNL under contract AC0376SF00098. We thank Andy Sessler and Swapan Chattopadhyay for their support and guidance and thank Wayne Greenway, William Strelo, and Bob Candelario for their excellent technical support.

\section{REFERENCES}

[1] Sessler, A.M. and Yu, S.S., "Relativistic Klystron Two-Beam Accelerator," Phys. Rev. Lett. 54, 889 (1987).

[2] Westenskow, G.A., and Houck, T.L., "Relativistic Klystron TwoBeam Accelerator," IEEE Trans. on Plasma Sci., 22, 750 (1994).

[3] Yu, S., et al, "Relativistic-Klystron Two-Beam Accelerator Based Power Source for a $1 \mathrm{TeV}$ Center-of-Mass Next Linear Collider Preliminary Design Report," LBNL LBID-2085.

[4] Houck, T.L., and Westenskow, G.A., "Prototype Microwave Source for a Relativistic Klystron Two-Beam Accelerator" IEEE Trans. on Plasma Sci. 24, 938 (1996).

[5] Registered name of Allied-Signal, Inc.

[6] Registered name of Corning Glass Works.

[7] Smith, C.H., and Barberi, L., "Dynamic Magnetization of Metallic Glasses," in Proc. of the 5th. IEEE Int'1 Pulsed Power Conf., 1985. 


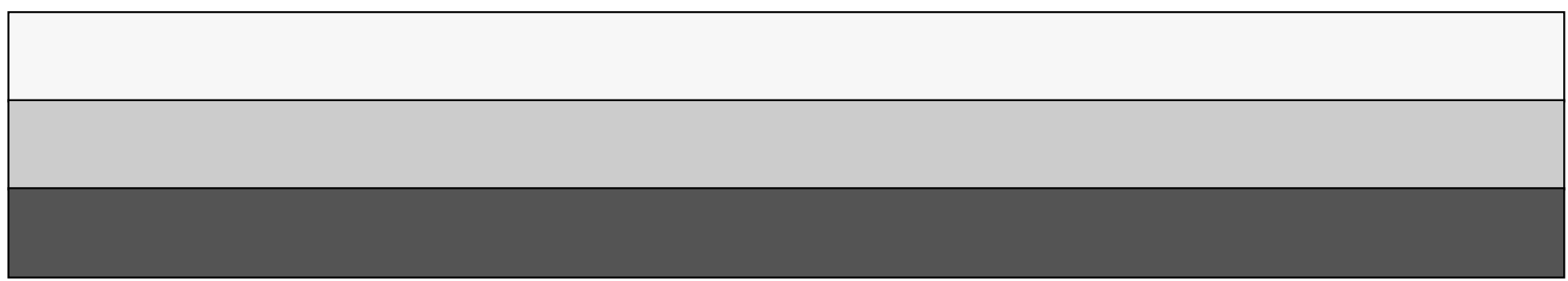

